\title{
Rumah Susun dengan Pendekatan Arsitektur BERKELANJUTAN Di MANGgarai, JAKARTA SELATAN
}

\author{
Yusniarti Apriza, Tri Joko Daryanto, Amin Sumadyo \\ Program Studi Arsitektur \\ Fakultas Teknik \\ Universitas Sebelas Maret Surakarta \\ Email : yusapr12@gmail.com
}

\begin{abstract}
Vertical Housing still become the solution of fulfilling housing needs as dense and slum settlement spread, such as in Manggarai, South Jakarta. Vertical Housing which had been built in Jakarta which had to do a fast construction sometimes ignore the social and economic factors of occupants, as well as the impact of construction to environment. Therefore, the construction of Vertical Housing has to integrate the social, economic, and environmental factor. The problem of design is how to design a form of building such as space and building façade which able to facilitate activities and occupants' need which is affected by site conditions and social life of occupants. This Vertical Housing aims to get spaces for activities and fulfilling the needs of occupants in the present and the future, and minimizing negative impacts of construction to environment. Design methode based on the concept of Sustainable Architecture because it considers the balancing of social, economic and environmental factors. The implementation of Sustainable Architecture is done by applying five Sustainable Architecture chosen aspects, such as sustainable site and land-use, sustainable energy, sustainable material, sustainable water, and sustainable community. These design aspects of Sustainable Architecture will result some concepts such as provision of shared social and economy spaces, green open spaces, the use of durable and eco-friendly materials, building façade responds to climate, and waste treatment system.
\end{abstract}

Keywords: Economic, Environment, Social, Sustainable Architecture, Vertical Housing

\section{PENDAHULUAN}

Kebutuhan tempat tinggal yang terus bertambah tidak sejalan dengan kenyataan yang dihadapi oleh daerah perkotaan, khususnya Jakarta bahwa lahan yang tersedia semakin terbatas dan nilai jual lahan yang cukup tinggi. Perhitungan kekurangan kebutuhan rumah (backlog) di Jakarta mencapai tujuh ratus ribu rumah dalam kurun waktu sepuluh tahun terakhir sampai tahun 2013 atau bertambah sekitar tujuh puluh ribu kebutuhan rumah setiap tahunnya berdasarkan RPJMD (Rencana Pembangunan Jangka Menengah Daerah) DKI Jakarta tahun 20132017. Terbatasnya lahan memicu permukimanpermukiman padat dan kumuh di Jakarta semakin menjamur sehingga pembangunan vertikal, khususnya Rumah Susun sebagai hunian sangat penting untuk diterapkan dalam pembangunan saat ini dan seterusnya.

Rumah Susun yang sudah lama terbangun di Jakarta yang dituntut untuk dibangun cepat kerap menimbulkan beberapa permasalahan yang mengabaikan aspek sosial dan ekonomi warga, serta dampak pembangunan terhadap lingkungan. Permasalahan tersebut, antara lain lokasi Rumah Susun yang kurang strategis, yakni jauh dari rute angkutan umum, akses perekonomian, dan sarana umum seperti pasar; minimnya ruang-ruang sosial dan terbuka publik; belum adanya sistem pengelolaan sampah yang dapat meminimalisir pembuangan ke luar area Rumah Susun dan penanganan limbah air kotor yang masih membebani aliran air pada drainase dan sungai. Permasalahan-permasalahan pada Rumah Susun tersebut membuktikan bahwa pembangunan tersebut belum dapat merespon kebutuhan penghuni dan belum tanggap lingkungan.

Pemilihan lokasi di Manggarai, Jakarta Selatan karena direncanakan akan dibangun Rumah Susun yang tercantum di dalam 
Rencana Tata Ruang Wilayah DKI Jakarta 2030 yakni akan dilakukan pengembangan di wilayah Manggarai untuk kegiatan campuran antara perkantoran, perdagangan dan jasa, serta permukiman vertikal (Rumah Susun) yang terjangkau dengan sarana transportasi umum. Pembangunan Rumah Susun di Manggarai juga sebagai respon masih adanya pemukiman kumuh, khususnya di bantaran Sungai Ciliwung yang memiliki kondisi hunian kurang layak. Permasalahan juga muncul pada pemukiman di Manggarai, yaitu minimnya ruang terbuka hijau dan publik; usaha perekonomian warga yang merupakan potensi, seperti pasar dan toko-toko atau warung yang memanfaatkan badan jalan karena terbatasnya lahan; kehidupan bantaran sungai yang tidak terkendali mengakibatkan pola kehidupan warga yang membuang limbah air kotor dan sampah langsung ke sungai sehingga dapat mengakibatkan pencemaran dan banjir. Oleh karena itu, pembangunan Rumah Susun di Manggarai perlu mempertimbangkan faktor sosial, ekonomi, dan lingkungan yang dapat meningkatkan kualitas hidup penghuni Rumah Susun.

$$
\text { Menanggapi permasalahan- }
$$

permasalahan pada Rumah Susun dan kondisi pemukiman di Manggarai yang terkait dengan aspek sosial, ekonomi, dan lingkungan, maka dalam perencanaan dan perancangan Rumah Susun perlu adanya pendekatan desain yang dapat menjadi solusi dari permasalahan tersebut. Arsitektur Berkelanjutan (Sustainable Architecture) yang memiliki tiga pilar dasar, yakni ekonomi, sosial, dan lingkungan yang terintegrasi secara seimbang dan selaras dipilih sebagai pendekatan desain Rumah Susun yang bertujuan untuk memenuhi kebutuhan penghuni saat ini dan yang akan datang, serta meminimalkan dampak negatif pembangunan bagi lingkungan.

\section{METODE}

Metode yang digunakan dalam perancangan Rumah Susun di Manggarai, Jakarta Selatan ini didasarkan pada pendekatan Arsitektur Berkelanjutan. Terdapat tiga pilar dasar Arsitektur Berkelanjutan, yakni sosial, ekonomi, dan lingkungan (Williams, 2007). Ketiga pilar dasar tersebut dijabarkan ke dalam enam aspek Arsitektur Berkelanjutan (Sassi, 2006). Berdasarkan pertimbangan keefektifan penerapan, hanya lima aspek yang diterapkan karena satu aspek yang lain memiliki strategi penerapan yang sudah terwakilkan oleh kelima aspek tersebut. Kelima aspek Arsitektur Berkelanjutan yang diterapkan, antara lain:

1. Tata Guna Tapak dan Lahan Berkelanjutan (Sustainable Site and Land-Use)

Strategi desain meliputi tapak sesuai rencana tata ruang kota, terjangkau transportasi dan fasilitas publik, penyediaan ruang terbuka hijau, dan penyediaan pedestrian. Penerapan dilakukan pada pemilihan lokasi dan pengolahan tapak.

2. Energi Berkelanjutan (Sustainable Energy)

Strategi desain meliputi penerapan sistem pencahayaan dan penghawaan alami dan menerapkan energi terbarukan. Penerapan dilakukan pada penentuan bentuk, tata massa, dan tampilan bangunan, serta utilitas bangunan.

3. Material Berkelanjutan (Sustainable Material)

Strategi desain meliputi durabilitas kualitas material, menggunakan material alam, material daur ulang atau yang bisa didaur ulang, material tidak mengandung VOC (Voltile Organic Compound). Penerapan dilakukan pada penggunaan material bangunan.

4. Air Berkelanjutan (Sustainable Water),

Strategi desain meliputi penggunaan sistem pengolahan air kotor yang tidak mencemari lingkungan, sistem daur ulang air kotor, dan sistem penampungan dan pengolahan air hujan. Penerapan dilakukan pada sistem utilitas air kotor dan air hujan.

5. Masyarakat Berkelanjutan (Sustainable Community)

Strategi desain meliputi penyediaan fasilitas untuk mengasah keterampilan, pendidikan, kesehatan, dan hiburan; lingkungan yang alami bagi pengguna berupa ruang terbuka hijau atau taman, penyediaan ruang bersama yang menarik, aman, dan nyaman; serta wadah pengelolaan sampah bersama sebagai agar penghuni sadar terhadap lingkungan. Penerapan dilakukan pada penyediaan kebutuhan ruang, pengolahan lansekap pada tapak, dan sistem pengelolaan sampah. 


\section{ANALISIS}

Analisis pada perencanaan dan perancangan Rumah Susun, meliputi:

\subsection{Analisis Peruangan}

1. Tujuan: kebutuhan dan kelompok zona ruang pada Rumah Susun.

2. Dasar pertimbangan: jenis pelaku dan kegiatan.

3. Hasil:

Kebutuhan ruang yang diwadahi menghasilkan kelompok zona ruang berdasarkan pelaku dan jenis kegiatan (lihat Gambar 1).

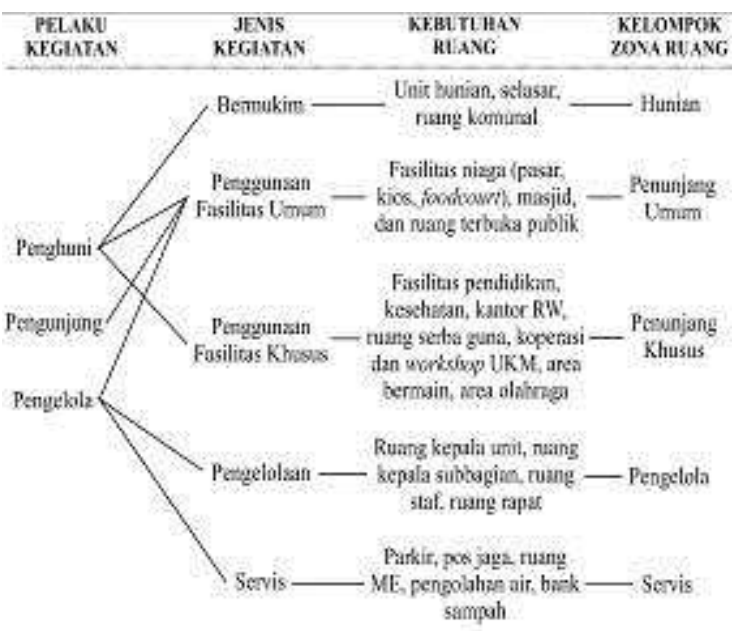

Gambar 1. Hubungan Pelaku, Jenis Kegiatan, Kebutuhan dan Kelompok Zona Ruang

\subsection{Analisis Tapak}

\subsubsection{Analisis Lokasi Tapak}

Dasar utama dalam pemilihan tapak adalah sesuai dengan Rencana Detail Tata Ruang DKI Jakarta Tahun 2014 bahwa tapak terpilih termasuk dalam zona Rumah Susun.

1. Tujuan: lokasi yang strategis sesuai kebutuhan Rumah Susun.

2. Dasar pertimbangan: luasan tapak yang cukup, kemudahan akses dari berbagai arah, terjangkau sarana dan prasarana publik, terjangkau jalur dan sarana transportasi.

3. Lokasi terpilih: Jl. Manggarai Utara 1, Kecamatan Manggarai, Jakarta Selatan (lihat Gambar 2).

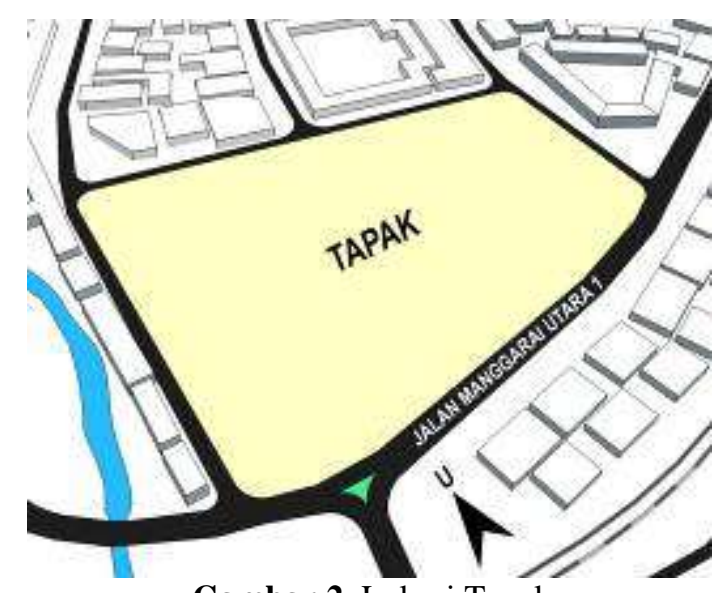

Gambar 2. Lokasi Tapak

\subsubsection{Analisis Pencapaian}

1. Tujuan: main entrance, side entrance, dan sirkulasi dalam tapak.

2. Dasar pertimbangan: kemudahan akses bagi kendaraan dan pejalan kaki, sirkulasi tapak yang aksesibel, arus kendaraan dan potensi jalan, tingkat keamanan.

3. Proses analisis dan hasil (lihat Gambar 3):

a. Main Entrance (ME)

Mudah dijangkau dan terlihat dengan jelas, menghadap langsung ke arah jalan untuk kemudahan sirkulasi kendaraan masuk dan ke luar tapak, serta dekat dengan jalur kendaraan umum. ME berada pada sisi selatan tapak dengan penambahan jalur lambat.

b. Side Entrance (SE)

Tidak mengganggu keberadaan ME, membantu akses sirkulasi penghuni dan servis (truk angkut sampah). SE berada di sisi barat dan timur tapak.

c. Sirkulasi

Sirkulasi (kendaraan maupun pedestrian) di dalam tapak mengelilingi bangunan untuk kemudahan akses pengguna dan mobil pemadam kebakaran. 


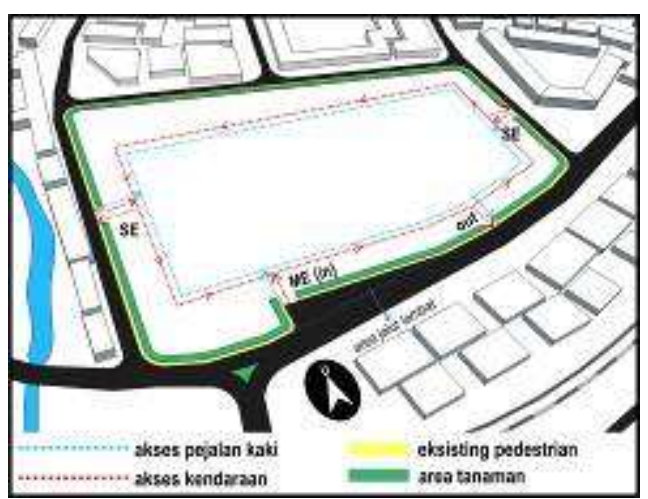

Gambar 3. Pencapaian dan Sirkulasi pada Tapak

\subsubsection{Analisis Pemintakatan}

1. Tujuan: mintakat (zoning) sesuai kelompok zona ruang.

2. Dasar pertimbangan: faktor pencapaian ke dalam tapak, fungsi kegiatan tiap kelompok ruang, tingkat privasi dan hubungan ruang secara makro.

3. Proses analisis:

Pemintakatan berdasarkan identifikasi persyaratan zona ruang yang terkait dasar pertimbangan. Terdapat lima zona pada bangunan Rumah Susun ini, yaitu zona hunian, penunjang umum, penunjang khusus, pengelola, dan servis (lihat Gambar 4).

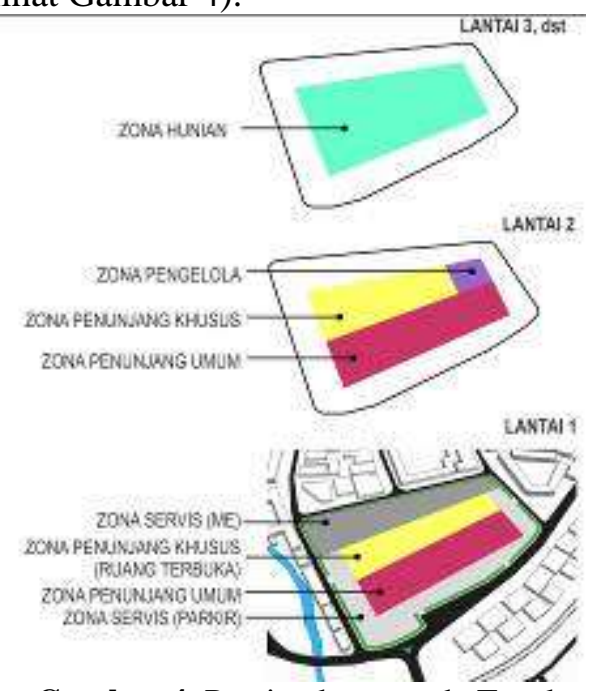

Gambar 4. Pemintakatan pada Tapak

\subsubsection{Analisis Lansekap}

1. Tujuan: lansekap pada tapak.

2. Dasar pertimbangan: adanya vegetasi sebagai peneduh, peredam kebisingan, penyerap polusi, dan dapat dimanfaatkan penghuni; perkerasan yang juga berfungsi sebagai peresapan; komponen lansekap menyesuaikan kebutuhan penghuni dan pendukung bangunan Rumah Susun.

3. Proses analisis:

Lansekap terdiri dari softscape dan hardscape. Softscape berupa taman yang dilengkapi dengan vegetasi jenis peneduh atau peredam kebisingian yang sebagian besar berada pada tepi tapak yang berbatasan dengan jalan. Softscape berupa vegetasi apotek hidup berada pad taman di antara massa bangunan. Hardscape berupa perkerasan lansekap menggunakan paving untuk jalur kendaraan dan pedestrian dari entrance, grass block pada area parkir dan pedestrian di sekeliling Rumah Susun, serta batu kerikil dan batu alam pada sirkulasi taman yang dapat digunakan sebagai area refleksi dan jogging track. Komponen lansekap berupa lampu taman solar sel tersebar pada taman dengan jarak antar lampu 5 meter dan gazebo sebagai wadah sosial pengguna di luar bangunan (lihat Gambar 5).

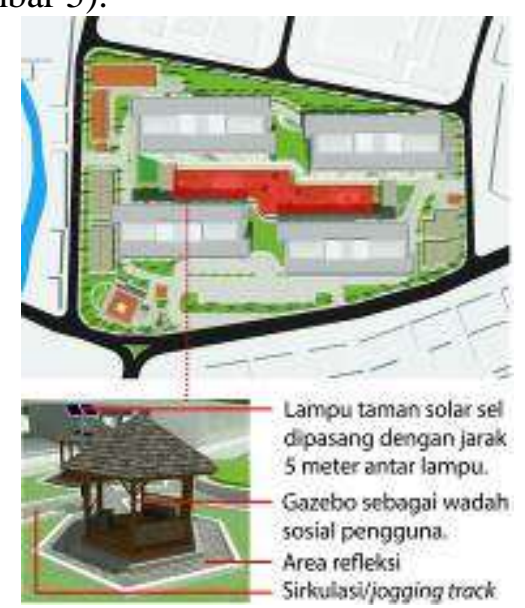

Gambar 5. Taman dan Komponen Lansekap

\subsection{Analisis Bentuk, Tata Massa dan Tampilan Bangunan}

Pertimbangan utama adalah penerapan aspek energi berkelanjutan (sustainable energy) terkait pertimbangan klimatologis dan pemanfaatan pencahayaan dan penghawaan alami.

\subsubsection{Analisis Bentuk Bangunan}

1. Tujuan: bentuk bangunan Rumah Susun.

2. Dasar pertimbangan: bentuk bangunan sedapat mungkin simetris, memungkinkan terciptanya ruang sosial dan ruang terbuka hijau, orientasi bangunan yang tepat, memanfaatkan pencahayaan, dan penghawaan alami.

3. Proses analisis: 
Bentuk massa Rumah Susun berawal dari penentuan bentuk dasar serta penataan peruangan unit-unit hunian, selasar, dan ruang komunal (Gambar 6). Ruang komunal besar yang akan berada di tiap tiga sampai empat lantai disediakan guna memaksimalkan wadah interaksi sosial penghuni dan dimungkinkannya wadah ekonomi dengan penataan ruang komunal yang berlawanan arah sekaligus ditempatkannya bukaan sehingga memungkinkan sistem ventilasi silang pada bangunan (Gambar 7). Dihasilkan enam modul bentuk Rumah Susun yang terdiri dari tiga jenis modul dasar, yaitu modul unit hunian dan ruang komunal skala kecil (modul A), serta dua modul unit hunian dan ruang komunal skala besar (modul B dan C) (lihat Gambar 8). Modul-modul tersebut disusun secara berselang-seling, sehingga menghasilkan bentuk fasad yang beragam (lihat Gambar 9).

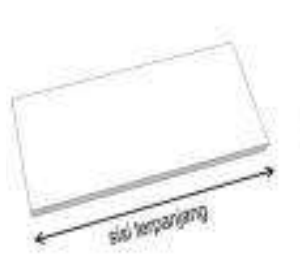

Bentuk dasar linie

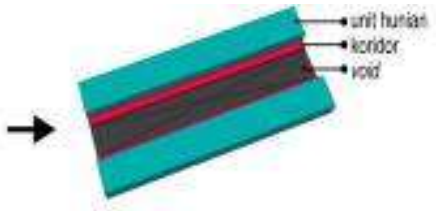

Unit hurian di bagian tertuar sisi agar mendapalkan pencarayaan dar perghawaan alami, di deparmya sirkulas single loaded comidor dengen waid
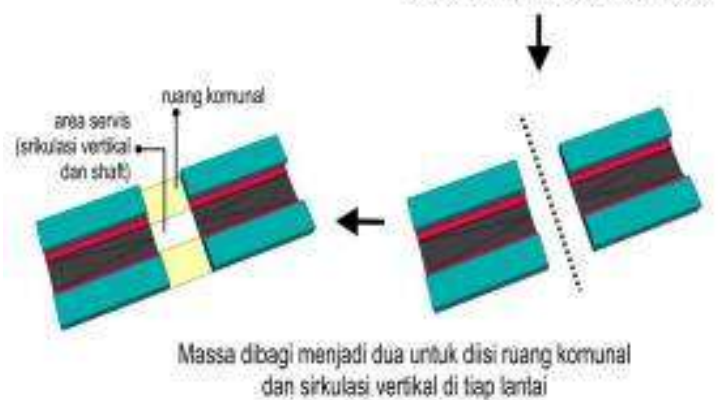

Gambar 6. Transformasi Bentuk Dasar

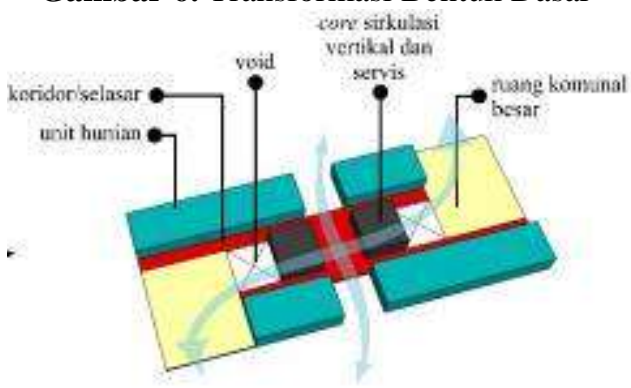

Gambar 7. Bentuk Dasar Area Hunian dan Ruang Komunal Besar

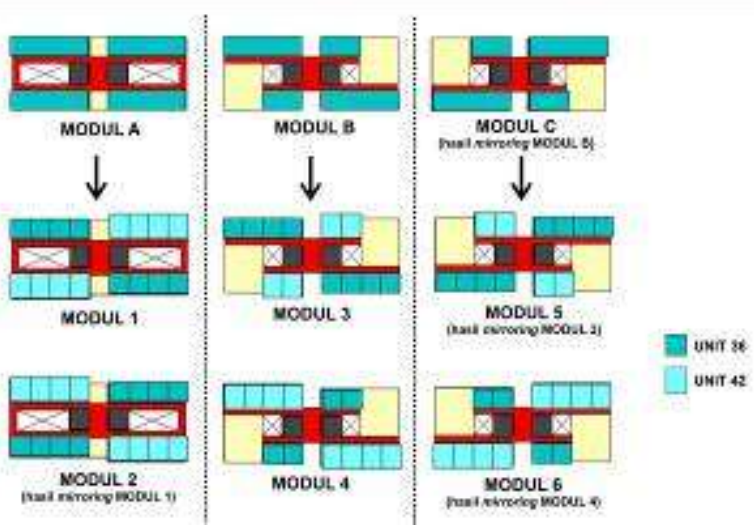

Gambar 8. Modul Bentuk Massa Rumah Susun
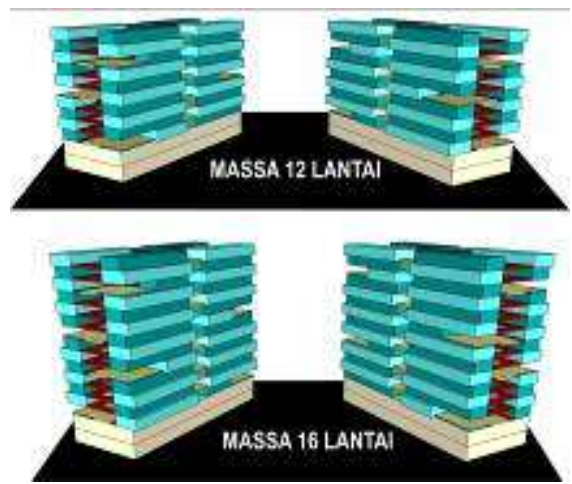

Gambar 9. Hasil Penyusunan Modul Bentuk Massa Rumah Susun

\subsubsection{Analisis Tata Massa}

1. Tujuan: penataan massa bangunan pada tapak.

2. Dasar pertimbangan: kelompok ruang dan pemintakatan.

3. Proses analisis dan hasil:

Massa bangunan ditempatkan sesuai dengan hasil pemintakatan pada tapak (lihat Gambar 10). Massa utama (Rumah Susun) ditempatkan di bagian tengah sebagai area kegiatan utama yang diorientasikan utara-selatan guna memanfaatkan pergerakan angin dan menghindari radiasi matahari berlebih. Massa pendukung berada di bagian sekeliling massa utama. Massa utama yang terdiri dari empat massa (ketinggian dua belas dan enam belas lantai) diperhitungkan jaraknya agar menjadi celah bagi sirkulasi udara dan cahaya matahari masuk ke dalam bangunan. Ruang yang terbentuk akibat jarak antar bangunan dapat dimanfaatkan sebagai ruang terbuka publik dan hijau. Massa utama yang terpisah-pisah dihubungkan oleh massa penghubung yang berfungsi 
sebagai komunal publik dan jembatan sebagai area hidroponik untuk wadah bertanam penghuni.

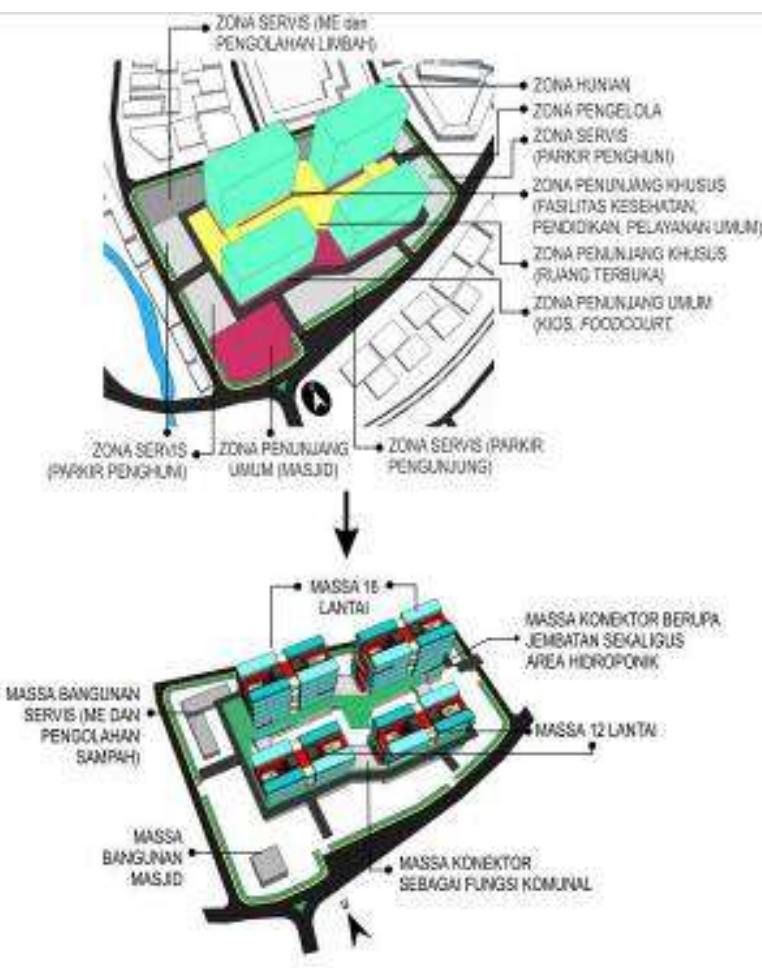

Gambar 10. Tata Massa Bangunan

\subsubsection{Analisis Tampilan Bangunan}

Tampilan bangunan yang akan dianalisis adalah komponen dinding, bukaan, dan atap.

1. Tujuan: tampilan bangunan Rumah Susun.

2. Dasar pertimbangan: penerapan bukaan (opening), sun shading, sistem ventilasi silang, atap yang ringan.

3. Proses analisis dan hasil:

\section{a. Dinding}

Penggunaan material beton pra cetak pada dinding luar dan bata ringan pada dinding dalam, finishing menggunakan cat warna putih yang dapat memantulkan cahaya matahari.

b. Bukaan

Penerapan berupa jendela dan ventilasi pada unit-unit hunian dan semua ruang. Elemen horizontal shading diterapkan pada jendela bagian luar unit hunian Rumah Susun (lihat Gambar 11). Pada sisi barat dan timur bangunan sebagai respon radiasi panas matahari berlebih, bukaan juga diberi elemen horizontal shading dengan penambahan wadah tanaman sebagai peredam panas dan filter udara (lihat Gambar 12).

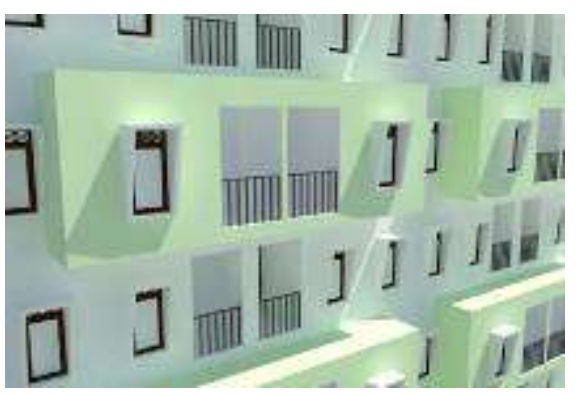

Gambar 11. Elemen Shading pada Jendela Luar Unit Hunian

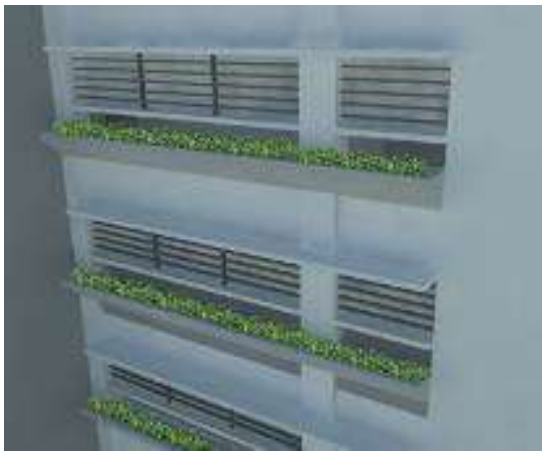

Gambar 12. Elemen Shading pada Bukaan Sisi Barat dan Timur Bangunan

c. Atap

Penggunaan atap pada bangunan Rumah Susun yang menerapkan void di dalam bangunan memiliki pertimbangan mampu memasukkan cahaya dan sebagai sirkulasi udara ke dalam atau ke luar bangunan, maka atap menggunakan jenis skylight dengan bentuk limasan yang mampu memasukan cahaya dari segala arah. Ventilasi pada atap skylight diterapkan pada sisi-sisi bagian bawah atap (lihat Gambar 12).

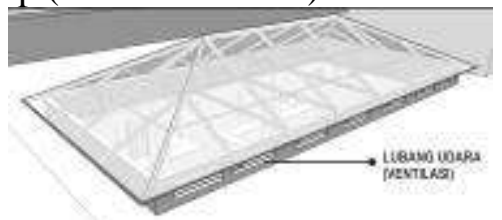

Gambar 13. Atap Skylight

\subsection{Analisis Sistem Struktur dan Material}

\subsubsection{Analisis Sistem Struktur}

1. Tujuan: sistem struktur sesuai dengan bangunan bertingkat tinggi.

2. Dasar pertimbangan: kemudahan dan cepat dalam hal pengerjaan saat konstruksi, bersifat kuat dan tahan lama, tidak 
mengganggu atau merusak lingkungan sekitar.

3. Proses analisis dan hasil (lihat Gambar 14:

a. Strukur Pondasi (Sub Structure)

Pondasi menggunakan pondasi dalam jenis bored pile yang tidak mengganggu lingkungan sekitar untuk menopang massa bangunan berlantai dua belas dan enam belas, sedangkan pondasi untuk massa penghubung yang terdiri dari dua lantai menggunakan pondasi footplat.

b. Struktur Badan (Supper Structure)

Bangunan Rumah Susun menggunakan struktur rangka dengan grid kolom dan balok menyesuaikan dimensi unit-unit hunian. Perkuatan struktur rangka didukung oleh dinding core (core wall) sebagai penempatan lift, tangga darurat, dan ruang shaft servis.

c. Struktur Atap (Upper Structure)

Kriteria struktur menggunakan jenis struktur yang ringan yang sesuai dengan jenis atap skylight limasan namun tetap kuat menahan beban. Struktur rangka baja ringan dipilih karena sesuai dengan kriteria tersebut.

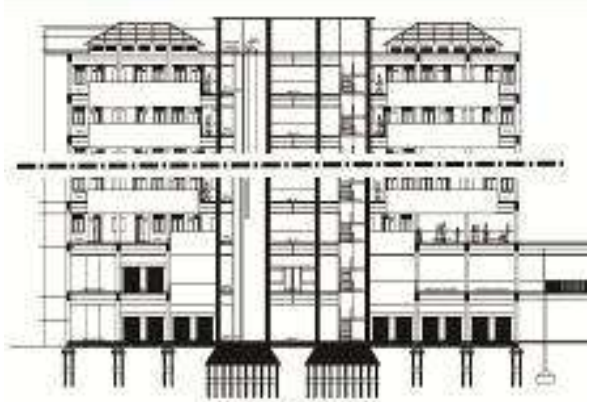

Gambar 14. Struktur Bangunan Rumah Susun

\subsubsection{Analisis Material}

1. Tujuan: material yang digunakan pada bangunan Rumah Susun.

2. Dasar pertimbangan: material memiliki daya tahan atau masa pakai lama sehingga mengurangi kegiatan atau biaya perawatan, bersifat ekonomis, memungkinkan dapat didaur ulang, tidak menghasilkan polusi atau tidak membahayakan kesehatan pengguna bangunan.

3. Proses analisis dan hasil:

a. Material Struktur
Kolom, balok, plan, dan pondasi yang memerlukan daya ketahahan dan masa pakai jangka panjang memerlukan material yang kuat sehingga digunakan beton dan baja sebagai tulangan pengisi beton.

b. Material Dinding

Penggunaan beton pra cetak pada bagian dinding luar dan bata ringan pada bagian dalam karena lebih ringan dan lebih kuat serta dapat didaur ulang. Finishing menggunakan cat yang tidak mengandung VOC.

c. Material Penutup Lantai

Penggunaan keramik dengan pertimbangan mudah perawatan atau dibersihkan, relatif murah, tidak lembab, aman terhadap penghuni, dan tahan lama. Lantai semen juga digunakan untuk area servis dan penunjang seperti pasar.

d. Material Penutup Atap

Penutup atap bersifat bidang transparan karena diterapkan pada skylight sehingga akan menggunakan polycarbonate dengan pertimbangan dapat menahan radiasi panas, lebih fleksibel sesuai dengan bentuk atap karena bentuknya seperti lembaran, dan lebih ringan dibandingkan kaca.

\subsection{Analisis Sistem Utilitas}

Pertimbangan utama adalah mampu mendukung aspek Arsitektur Berkelanjutan yang mendukung lingkungan, seperti aspek air berkelanjutan melalui sistem daur ulang air kotor dan aspek masyarakat berkelanjutan melalui kegiatan pengelolaan sampah bersama dengan mendaur ulang sampah.

\subsubsection{Sistem Pengelolaan Air Kotor dan Air Hujan}

1. Tujuan: sistem pengelolaan air kotor dan air hujan.

2. Dasar pertimbangan: tidak mengganggu kesehatan, lingkungan, penciuman, dan visual, serta dapat didaur ulang untuk dimanfaatkan kembali.

3. Analisis dan hasil:

Pengelolaan air kotor menerapkan sistem daur ulang dengan media biofilter anaerob-aerob (lihat Gambar 15) dan media sand filter dan carbon filter agar dapat digunakan kembali untuk 
penyiraman tanaman dan flushing toilet umum. Air kotor berupa greywater langsung dialirkan menuju bak pengolah limbah, yakni Sewage Treatment Plan (STP), sedangkan blackwater dialirkan terlebih dahulu menuju septictank dan air buangannya dialirkan menujua STP. Hasil olahan air dari STP difilter kembali, kemudian disimpan di dalam tangki penampungan. Air hujan yang jatuh pada atap langsung dialirkan ke tangki penampungan (tanpa difilter) karena tidak terlalu banyak mengandung zat beracun. Air hujan yang jatuh ke permukaan tanah akan diserap ke dalam tanah melalui lubang biopori yang tersebar di lingkungan Rumah Susun.

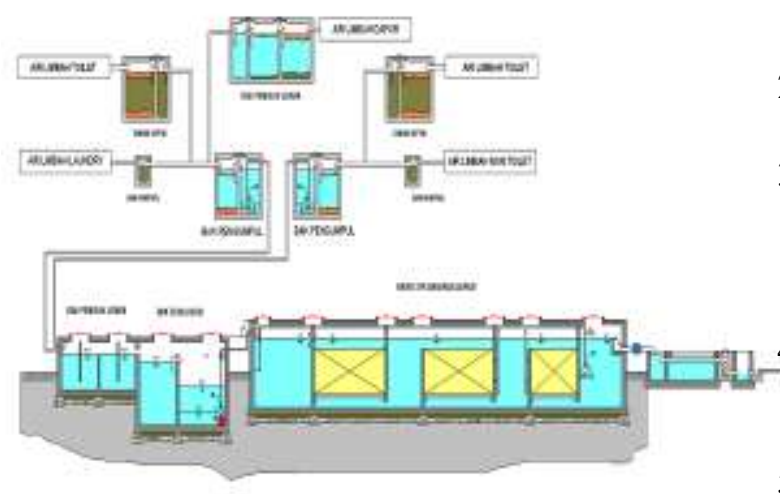

Gambar 15. Pengolahan Sistem Biofilter Aerob-Anaerob (http://www.kelair.bppt.go.id)

\subsubsection{Sistem Pengelolaan Sampah}

1. Tujuan: pengelolaan sampah organik dan anorganik.

2. Dasar pertimbangan: pembuangan sampah memudahkan penghuni secara vertikal, meminimalisir pembuangan ke Tempat Pembuangan Akhir (TPA), dan sistem daur ulang sampah.

3. Analisis dan hasil:

Sistem pembuangan sampah dibedakan antara organik dan anorganik. Pembuangan sampah melalui shaft sampah organik dan anorganik di tiap-tiap lantai untuk memudahkan penghuni. Sampah akan dikumpulkan pada tempat pengolahan sampah. Sampah anorganik yang didaur ulang dapat dimanfaatkan sebagai barang kerajinan melalui usaha bersama, sedangkan sampah organik akan diolah melalui biodigester yang akan menghasilkan pupuk cair dan biogas.
Biogas yang dihasilkan akan dijadikan sebagai bahan bakar cadangan bagi genset. Penghuni dapat menabung dengan sampah melalui bank sampah agar penghuni lebih peduli akan pentingnya sampah.

\section{KESIMPULAN (KONSEP DESAIN)}

Rancangan Rumah Susun ini memiliki konsep yang diharapkan mampu menyeimbangkan faktor sosial, ekonomi, dan lingkungan secara seimbang melalui penerapan aspek-aspek desain Arsitektur Berkelanjutan. Penerapan aspek desain tersebut ke dalam bangunan Rumah Susun mewujudkan beberapa konsep desain, antara lain:

1. Penyedian ruang-ruang bersama melalui selasar/koridor dan ruang komunal pada zona hunian, serta wadah perekonomian.

2. Penyediaan ruang terbuka hijau dan publik (lihat Gambar 16).

3. Bentuk, tata massa (lihat Gambar 17), dan tampilan bangunan (lihat Gambar 18) yang merespon iklim dan memanfaatkan sistem pencahayaan dan penghawaan alami.

4. Penggunaan struktur dan material yang mempertimbangkan ketahanan lama dan ramah lingkungan.

5. Sistem pengolahan limbah berupa daur ulang air kotor dan air hujan sebagai air untuk penyiraman tanaman atau flushing toilet umum dan pengolahan sampah anorganik sebagai usaha kerajinan bersama serta organik menjadi pupuk atau biogas sebagai sumber cadangan bahan bakar genset.

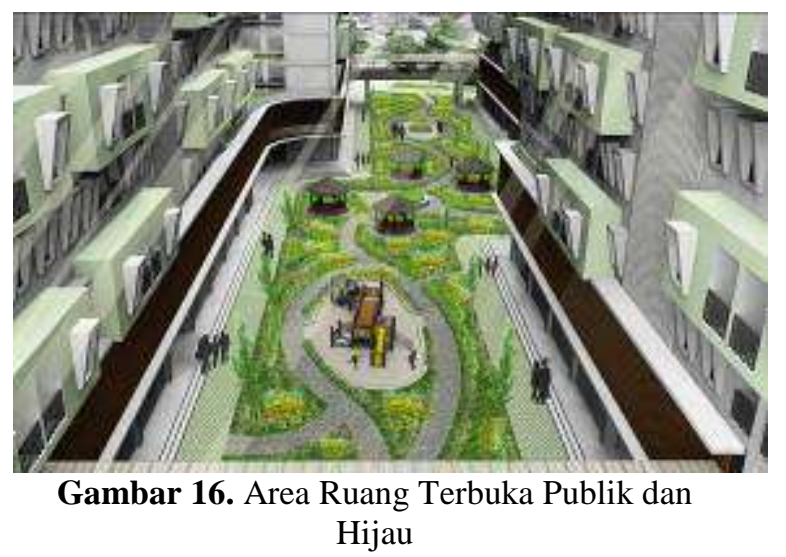




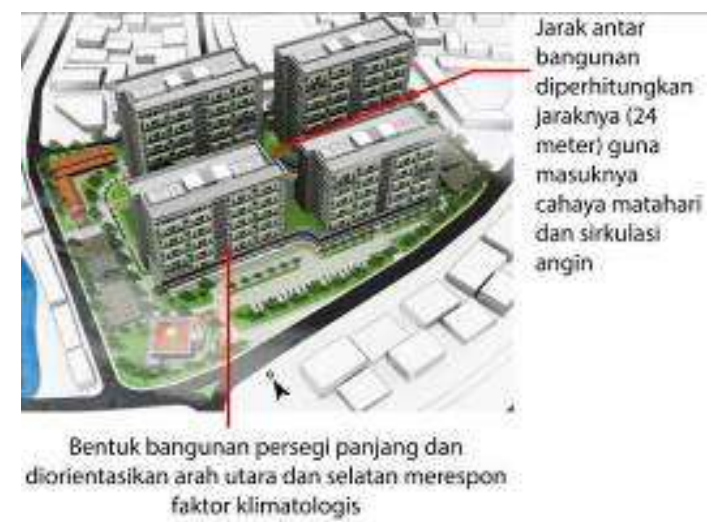

Gambar 17. Bentuk dan Tata Massa Bangunan

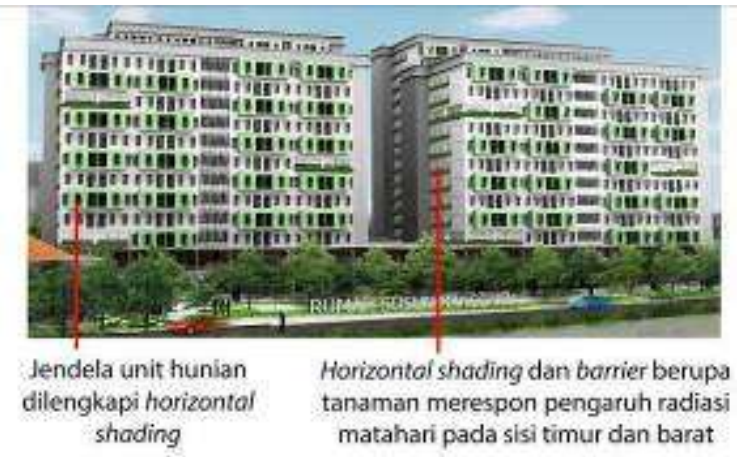

Gambar 18. Tampilan Bangunan

\section{REFERENSI}

Badan Perencanaan Pembangunan Daerah. 2012. Rencana Tata Ruang Wilayah DKI Jakarta 2030. http://bappedajakarta.go.id/?page_id= 1270

Badan Perencanaan Pembangunan Daerah. 2013. Peraturan Daerah Provinsi Daerah Khusus Ibukota Jakarta Nomor 2 Tahun 2013: Rencana Pembangunan Jangka Menengah Daerah Provinsi Daerah Khusus Ibukota Jakarta Tahun 2013 - 2017. Jakarta. http://bappedajakarta.go.id/?page_id=109 9.

Sassi, Paola. 2006. Strategies for Sustainable Architecture. New York: Taylor \& Francis.

Williams, Daniel E. 2007. Sustainable Design: Ecology, Architecture, and Planning. New Jersey: John Wiley \& Sons, Inc.

http://www.kelair.bppt.go.id 